\title{
Intermediates of rifamycin polyketide synthase produced by an Amycolatopsis mediterranei mutant with inactivated riff gene
}

\author{
Ansgar Stratmann, Christiane Toupet, Wolfgang Schilling, René Traber, \\ Lukas Oberer and Thomas Schupp
}

Novartis Pharma AG, Research, Core Technology Area, CH-4002 Basel, Switzerland
Author for correspondence: Thomas Schupp. Tel: +416132 47903. Fax: +41613243279. e-mail: thomas.schupp@pharma.novartis.com

Rifamycin B biosynthesis in Amycolatopsis mediterranei N/813 was inactivated by introducing a small deletion in the riff gene situated directly downstream of the rifamycin polyketide synthase (PKS) gene cluster. The corresponding mutant strain produced a series of linear intermediates of rifamycin B biosynthesis that are most probably generated by obstruction of the normal release of the end product of the rifamycin PKS. This result provides evidence that the riff gene product catalyses the release of the completed linear polyketide from module 10 of the PKS and the intramolecular macrocyclic ring closure by formation of an amide bond, as indicated by sequence similarity of this protein to amide synthases. The chemical structures of the new rifamycin polyketide synthase intermediates released from modules $\mathbf{4}$ to 10 were determined by spectroscopic methods (UV, IR, NMR and MS) and gave insight into the reaction steps of rifamycin ansa chain biosynthesis and the timing of the formation of the naphthoquinone ring. The intermediates released from modules 6 and 8 were isolated as lactones formed by the terminal carboxyl group; proton NMR double resonance and ROESY(rotated frame nuclear Overhauser enhancement spectroscopy) experiments enabled the deduction of the relative configurations in the linear chain which correspond to the known absolute stereochemistry of rifamycin $B$.

Keywords: antibiotic biosynthesis, ansamycins, amide synthase, gene replacement, pathway engineering

\section{INTRODUCTION}

Rifamycins are clinically important ansamycin antibiotics, composed of a naphthalenic chromophore spanned by a long aliphatic ansa chain. The rifamycins and the semisynthetic drugs derived from them exert their antibiotic activity by specific inhibition of bacterial DNA-dependent RNA polymerase (Wehrli, 1977). At higher concentrations, these antibiotics also inhibit the RNA-dependent DNA polymerase of retroviruses (Szabo et al., 1976). Although rifamycins are primarily used against Mycobacterium tuberculosis and Myco-

Abbreviations: PKS, polyketide synthase; AHBA, 3-amino-5-hydroxybenzoic acid. bacterium leprae, causative agents of tuberculosis and leprosy, respectively, they are also active against a variety of other organisms, including bacteria and viruses (Szabo et al., 1976; Oppenheim et al., 1986; Barakett et al., 1993; Bachs et al., 1992). Furthermore, it was shown recently that rifampicin-containing regimens are able to cure staphylococcal implant-related infections (Zimmerli et al., 1998).

The identification and sequencing of the rifamycin polyketide synthase (PKS) gene cluster by our group (Schupp et al., 1998) and by August et al. (1998) disclosed five genes, rifA-rifE, responsible for the synthesis of the rifamycin polyketide chain. The encoded multifunctional enzymes contain a total of ten PKS modules, which use 3-amino-5-hydroxybenzoic acid (AHBA) as a starter unit to catalyse successive rounds of polyketide 
chain elongation to build the polyketide backbone of the rifamycin molecule.

Our interest in further studying rifamycin B biosynthesis led us to undertake the inactivation of the riff gene, situated directly downstram of the PKS genes, and to analyse the effect of this mutation on rifamycin biosynthesis. The rifF gene product has been characterized as rifamycin amide synthase by sequence homologies to different arylamine $\mathrm{N}$-acetyltransferases (August et al., 1998) and the putative function of the RifF protein in rifamycin biosynthesis was suggested to be a cyclase, catalysing the formation of an intramolecular amide bond between the carboxyl end of the synthesized linear polyketide chain and the amino group of the AHBA starter unit (Chen et al., 1999).

In this paper we describe the inactivation of the rifF gene by introducing a $9 \mathrm{bp}$ deletion into the chromosomal rifF gene of the rifamycin $\mathrm{B}$ high-producing strain Amycolatopsis mediterranei N/813 (Ghisalba et al., 1984). We were able to isolate and characterize a series of linear intermediates of rifamycin B biosynthesis. Our results confirm the putative function of RifF postulated from sequence homology, and give new insights into the succession of biosynthetic steps during the rifamycin B biosynthesis.

\section{METHODS}

Bacterial strains and culture conditions. Amycolatopsis mediterranei N/813 (Ghisalba et al., 1984) a rifamycin highproducing strain (from the Novartis strain collection) and mutants of this strain were propagated in liquid medium NL148 (Schupp \& Divers, 1986) or on YMG agar (4 g yeast extract, $10 \mathrm{~g}$ malt extract, $4 \mathrm{~g}$ glucose and $18 \mathrm{~g}$ agar in 11 water, $\mathrm{pH} 7 \cdot 3$ ). Strain N/813 was cultivated in liquid YMG medium for genomic DNA isolation and in SOC medium (Hanahan, 1983) for preparation of electrocompetent cells. Cultures for rifamycin production were grown in $40 \mathrm{ml}$ liquid medium FBR42 [90 g sucrose, 70 g glucose, 32 g soybean flour,

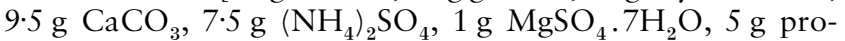
pylene glycol, $1 \mathrm{~g}$ sodium diethylbarbituric acid, $1 \mathrm{ml}$ trace elements solution $\left(1 \mathrm{~g} \mathrm{Fe}_{2}(\mathrm{SO} 4)_{3} .7 \mathrm{H}_{2} \mathrm{O}, 0.33 \mathrm{~g} \mathrm{CuSO}_{4} .5 \mathrm{H}_{2} \mathrm{O}\right.$, $5 \mathrm{~g} \mathrm{ZnSO}_{4} \cdot 7 \mathrm{H}_{2} \mathrm{O}, 0 \cdot 4 \mathrm{~g} \mathrm{MnSO}_{4} \cdot \mathrm{H}_{2} \mathrm{O}, 0 \cdot 2 \mathrm{~g} \mathrm{CoCl}_{2} \cdot 6 \mathrm{H}_{2} \mathrm{O}$ and $0.1 \mathrm{~g}$ ammonium molybdate tetrahydrate in $1 \mathrm{l}$ water) and $1 \mathrm{ml}$ antifoam B (Sigma) in $1 \mathrm{l}$ water, $\mathrm{pH} \mathrm{7 \cdot 0]}$ in $200 \mathrm{ml}$ shake flasks (one baffle).

Escherichia coli DH5 $\alpha$ (Hanahan, 1983) was used for propagation of plasmids and cloning of DNA. E. coli ET12567 (dam ${ }^{-} \mathrm{dcm}^{-}$hsdM: MacNeil et al., 1992) was used for preparation of plasmid DNA for transfer into A. mediterranei by electroporation. E. coli was grown in LB medium (Miller, 1972). For plasmid maintenance, tetracycline $\left(25 \mu \mathrm{g} \mathrm{ml}^{-1}\right)$, chloramphenicol $\left(50 \mu \mathrm{g} \mathrm{ml}^{-1}\right)$ or ampicillin $\left(50 \mu \mathrm{g} \mathrm{ml}^{-1}\right)$ were added where appropriate. Cultivation temperatures were $37^{\circ} \mathrm{C}$ for E. coli and $28^{\circ} \mathrm{C}$ for A. mediterranei.

Plasmids and construction of new cloning vectors. The E. coli cloning vector pUCBM21 (Boehringer Mannheim) was used for the construction of suicide plasmids for gene disruption and gene replacement in $A$. mediterranei. To remove the single PstI site in the multiple-cloning site of pUCBM21, the plasmid was cleaved with PstI, treated with Klenow enzyme
(Boehringer Mannheim) and religated, giving plasmid pBM21*. The aacC4 cassette (Blondelet-Rouault et al., 1997), which confers apramycin resistance in E. coli and $A$. mediterranei, was introduced into the HindIII site of pBM21* as a $1.7 \mathrm{~kb}$ HindIII DNA fragment resulting in plasmid pASN3.

Electroporation of $A$. mediterranei N/813. A. mediterranei $\mathrm{N} / 813$ cells were harvested after $2 \mathrm{~d}$ growth in $40 \mathrm{ml}$ liquid SOC medium and washed three times in $10 \%$ glycerol at room temperature. The cells were resuspended in $4 \mathrm{ml} 10 \%$ glycerol containing $40 \mu \mathrm{g}$ lysozyme $\mathrm{ml}^{-1}$ and incubated for $20 \mathrm{~min}$ with gentle shaking (50 r.p.m.). After one washing step with $4 \mathrm{ml}$ $10 \%$ glycerol at $4{ }^{\circ} \mathrm{C}$ the cells were resuspended in $1.6 \mathrm{ml}$ icecold $10 \%$ glycerol and used immediately for electroporation. Plasmid DNA $(0.5-1.0 \mu \mathrm{g})$ was heat denatured $\left(5 \mathrm{~min}\right.$ at $\left.95^{\circ} \mathrm{C}\right)$ before it was mixed with $200 \mu \mathrm{l}$ cell suspension on ice. The mixture was immediately transferred into a $0.2 \mathrm{~cm}$ electrocuvette and a single electric pulse (Gene Pulser II; Pulse Controller Plus; Bio-Rad) was applied $(1.5-2.0 \mathrm{kV} ; 1000 \Omega$; $25 \mu \mathrm{F})$. The electroporated mycelium was immediately diluted with $0.8 \mathrm{ml}$ YMG medium, transferred to $10 \mathrm{ml} \mathrm{YMG}$ medium and incubated for $14-16 \mathrm{~h}$ at $28{ }^{\circ} \mathrm{C}$ with vigorous shaking (250 r.p.m.). The whole culture was then plated on a YMG agar plate containing $50 \mu \mathrm{g}$ apramycin $\mathrm{ml}^{-1}$.

Genetic procedures. Chromosomal DNA isolation was carried out according to Pospiech \& Neumann (1995). DNA fragments were recovered from agarose gels using the Qiaex Kit (Qiagen) and DNA labelling was performed with $\left[{ }^{32} \mathrm{P}\right] \mathrm{dCTP}$ using a Nick Translation Kit (Boehringer Mannheim). Southern hybridization experiments were performed using Hybond-N + nylon membranes (Amersham) following the manufacturer's alkali blotting protocol. Genetic procedures involving E. coli, and in vitro DNA manipulations were performed according to standard protocols (Sambrook et al., 1989).

DNA sequencing. DNA sequencing was by the dideoxynucleotide chain-termination method with an automated laser fluorescence sequencer (Applied Biosystems, ABI PRISM377). Sequencing reactions were done with the standard reverse primer using the ABI PRISM BigDye Terminator Cycle Sequencing Kit (Perkin Elmer) according to the supplier's instructions.

HPLC analysis. For HPLC analysis of metabolites, $A$. mediterranei culture broths were mixed $1: 1$ with butanol and shaken for $4 \mathrm{~h}$ at room temperature (150 r.p.m.). After centrifugation $(10 \mathrm{~min}, 5000 \mathrm{~g})$ the butanol phase was separated and 10-20 $\mu \mathrm{l}$ was analysed by HPLC (Merck model L-6200) using a $4.6 \times 100 \mathrm{~mm}$ Symmetry C18, 3.5 mm column (Waters) with gradient elution (5 min linear gradient of $0-50 \%$ acetonitrile, hold for $2 \mathrm{~min}, 5 \mathrm{~min}$ linear gradient of $50-100 \%$ acetonitrile, hold for $3 \mathrm{~min}, 2 \mathrm{~min}$ linear gradient of $100-0 \%$ acetonitrile) using a phosphate $(0.55 \%$ orthophosphoric acid, $\mathrm{pH}$ adjusted to 4.5 with triethylamine)/ acetonitrile buffer system. The region from 200 to $500 \mathrm{~nm}$ was scanned with a DAD-System L-4500 (Merck) and the spectra were compared with a rifamycin B standard.

Isolation of AHBA and rifamycin-biosynthesis intermediates. The culture broth of a 11 fermentation of mutant $3 / 1$ in FBR42 medium was extracted twice with ethyl acetate (1 l each) and the crude extract was defatted with hexane $(3 \times 500 \mathrm{ml})$. The complex mixture $(5 \cdot 4 \mathrm{~g})$ was submitted to gel filtration on Sephadex LH20 with methanol. Fractions 3 and $4(1.87 \mathrm{~g})$, containing UV-active compounds, were further separated by reversed-phase chromatography on LiChrospher RP18 $12 \mu \mathrm{m}$ (200 g) using a gradient composed of watertriethylammoniumformiate buffer (A) and acetonitrile (B) from $0-60 \%$ B. Final purification was performed by pre- 

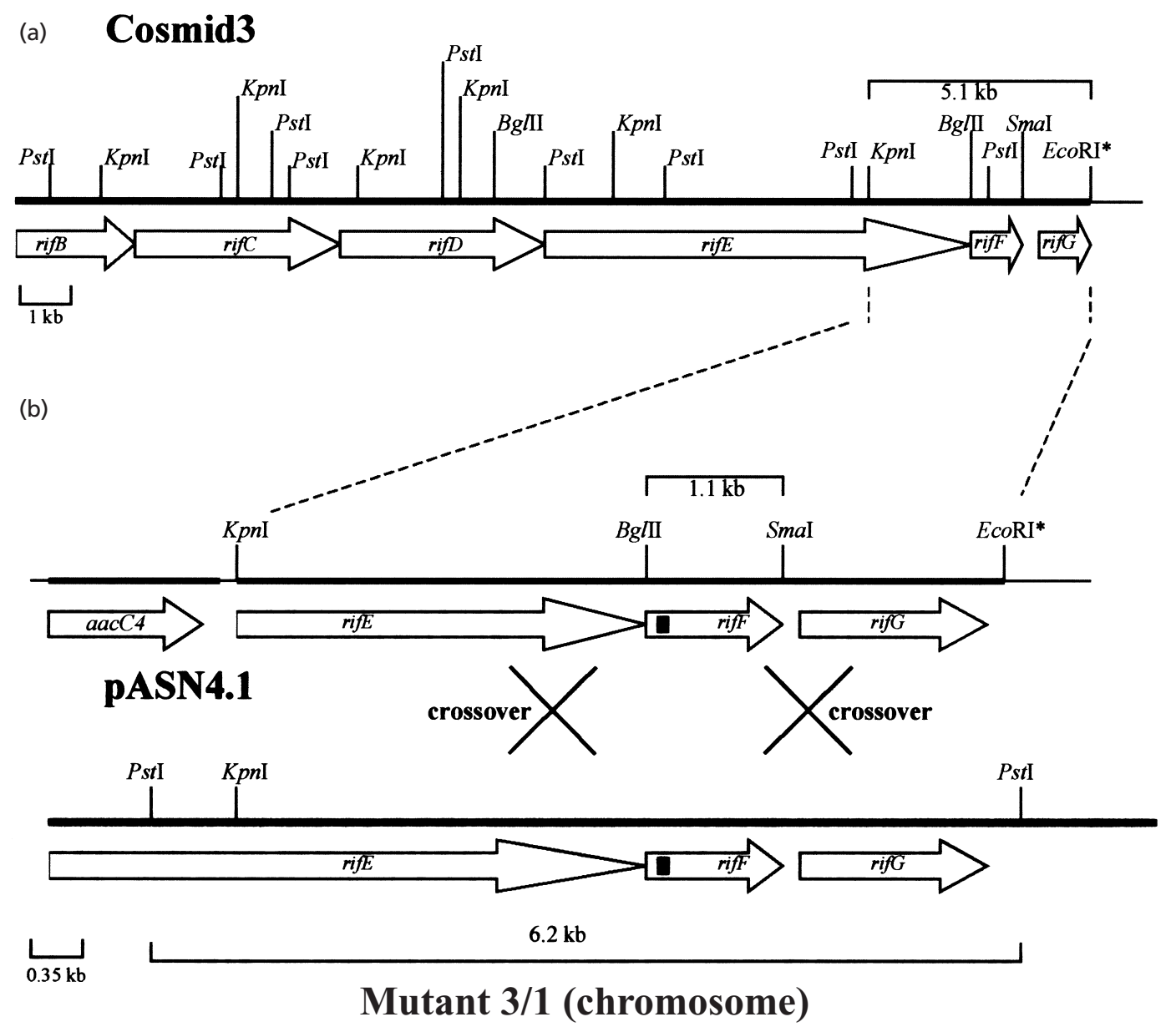

Fig. 1. Genomic region of $A$. mediterranei containing the riff gene and scheme for Pstl deletion in riff and gene replacement. (a) Restriction map of the riff gene, the upstream PKS genes rifC $-E$ and the downstream rifG gene (aminodehydroquinate synthase), cloned in cosmid 3. (b) Subcloned $5.1 \mathrm{~kb} K$ pnl-EcoRI DNA fragment in the suicide plasmid pASN4.1 and the respective chromosomal region of mutant 3/1, with the mutated riff gene introduced by gene replacement through a double crossover (lower map). The short deletion introduced in riff is shown as a black box. The indicated $1.1 \mathrm{~kb} B g / l \mathrm{l}-\mathrm{Smal}$ DNA fragment was used for DNA sequencing to analyse the deletion in the rifF gene. The indicated $6 \cdot 2 \mathrm{~kb}$ Pstl chromosomal DNA fragment of mutant 3/1 was detected by Southern hybridization (Fig. 2). Only one Smal site, relevant for the work, is shown and the EcoRI* site originates from the cosmid vector pWE15. The thin lines represent cosmid DNA on either side of the inserts.

parative TLC using the systems $\mathrm{CH}_{2} \mathrm{Cl}_{2} / \mathrm{MeOH} / \mathrm{H}_{2} \mathrm{O}$ $80: 17 \cdot 5: 2$ and $88: 11: 1$ by vol.

The yields were $2.3 \mathrm{~g}$ AHBA, $90 \mathrm{mg}$ compound 1, $18 \mathrm{mg} \mathrm{2,}$

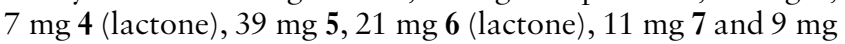
8. From a cultivation on a 51 scale which was worked up analogously, $44 \mathrm{mg}$ compound $\mathbf{3}$ was isolated.

Spectroscopic measurements. The UV-absorption spectra were recorded in methanol with a Perkin Elmer Lambda 9 spectrophotometer. The IR spectra were taken in $\mathrm{KBr}$ pellets on a FT-IR spectrometer BRUKER IFS 66. ${ }^{1} \mathrm{H} /{ }^{13} \mathrm{C}$ NMR spectra were recorded in $d_{6}$-DMSO on a Bruker Avance DMX-500 spectrometer at $500 \mathrm{MHz}$ with tetramethylsilane as the internal standard. Electrospray mass spectra were measured with a Finnigan SSQ-7000 MS spectrometer.

\section{RESULTS}

\section{Construction of a small deletion in the riff gene of A. mediterranei}

The rifF gene is located directly downstream of the gene cluster for the rifamycin PKS (August et al., 1998). The gene contains one Pst site in the 780 bp ORF, 81 bp after the GTG start codon. This site was chosen to introduce a short deletion in rifF. For this mutagenesis a $5 \cdot 1 \mathrm{~kb} K p n \mathrm{I}-E c o$ RI fragment containing the rifF gene was isolated from the previously described cosmid 3 (Schupp et al., 1998) (Fig. 1) and subcloned into pASN3, a pUCBM21 derivative containing the apramycin resistance gene (aacC4) that allows selection in E. coli and A. mediterranei (see Methods). The resulting plasmid, 


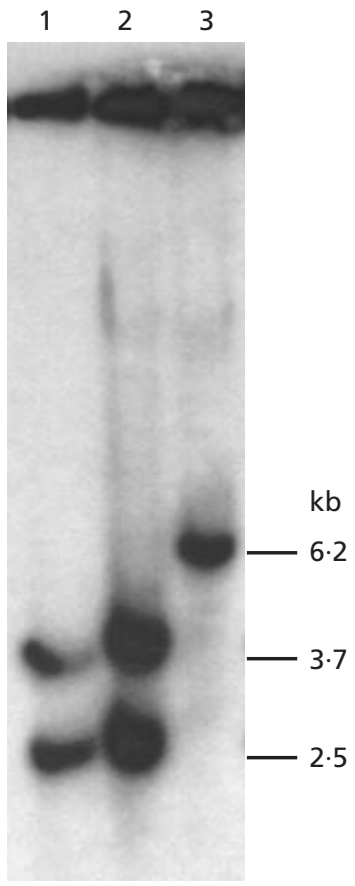

Fig. 2. Hybridization pattern of Pstl-digested chromosomal DNA from $A$. mediterranei N/813 (lane 1) and the two mutant strains 4/1 (lane 2) and 3/1 (lane 3) with the $5 \cdot 1 \mathrm{~kb}$ EcoRI-Kpnl DNA fragment (Fig. 1) as the radioactive probe. Fragment size was determined by reference to a $1 \mathrm{~kb}$ DNA ladder and HindIIIdigested lambda DNA (Gibco-BRL).

pASN4, containing the chromosomal KpnI-EcoRI fragment of $A$. mediterranei, was used to introduce the deletion in rifF by PstI digestion, treatment with Klenow enzyme and self-ligation resulting in plasmid pASN4.1 that has lost the PstI site.

\section{Introduction of the mutated riff gene into A. mediterranei by gene replacement}

To introduce the mutated rifF gene into A. mediterranei $\mathrm{N} / 813$, electrocompetent cells of this strain were transformed with plasmid pASN4.1 by electroporation. After $8 \mathrm{~d}$ growth of the transformed cells on YMG agar plates with apramycin, distinct single colonies became visible. Five of these apramycin-resistant A. mediterranei transformants were analysed by Southern hybridization using the aac 4 gene of pASN4.1 as the radioactive probe. This analysis showed that these transformants contained pASN4.1 integrated into the chromosome by a single crossover through homologous recombination (data not shown). One of these A. mediterranei transformants was selected for further analysis and cultivated in the production medium FBR42. HPLC analysis of the extract showed that rifamycin B production is blocked in this strain.

To enable the second crossover, the selected $A$. mediterranei transformant was cultivated four times in liquid NL148 medium without apramycin $(5 \%$ inoculation and $3 \mathrm{~d}$ cultivation each time). Apramycinsensitive mutants were then detected by replica plating single colonies, derived from the last NL148 culture, on YMG agar with and without apramycin. From about 1000 colonies tested, two apramycin-sensitive mutants were detected and chosen for further analysis.

\section{Characterization of two double-crossover mutants}

Southern-blot analysis of PstI-digested chromosomal DNA using the $5 \cdot 1 \mathrm{~kb} K p n \mathrm{I}-E c o R I$ DNA fragment containing rifF as the probe clearly demonstrated the elimination of the single Pst I site in the rifF gene in the chromosome of mutant $3 / 1$. The hybridization pattern of this mutant showed only one band, $6.2 \mathrm{~kb}$ in size. In contrast to this, the parental strain N/813 and the other mutant, 4/1, gave two hybridizing Pst I fragments, $3 \cdot 7 \mathrm{~kb}$ and $2.5 \mathrm{~kb}$ in size (Fig. 2). These hybridization data are in agreement with the restriction pattern expected for replacement of the DNA fragment containing the nonmutated rifF gene with the one lacking the internal Pst $\mathrm{I}$ site in mutant $3 / 1$ and the reconstitution of the parental rifF gene in mutant $4 / 1$. This conclusion was confirmed by HPLC analysis of rifamycin B production by the two mutants. Mutant $3 / 1$ does not produce rifamycin $B$ in the production medium FBR42 whereas mutant 4/1 produces about the same amount as the parental strain $\mathrm{N} / 813$.

The deletion in the rifF gene of mutant $3 / 1$ was analysed by DNA sequencing. To obtain this information, the internal $1.1 \mathrm{~kb} B g l I I-S m a I$ DNA fragment out of the $5.1 \mathrm{~kb} K p n \mathrm{I}-E c o$ RI fragment of pASN4.1 was cloned into the BamHI-SmaI sites of pUCBM21 in E. coli. The resulting plasmid was named pASN4.2 and the sequence of the cloned DNA fragment was determined. As shown in Fig. 3, mutant $3 / 1$ has an unexpected 9 bp deletion in the rifF gene, derived from 3' exonuclease activity of the Klenow enzyme. This mutation results in a loss of three amino acids (Q, K and $S$ ) and a change from $L$ to $R$ at position 29 of the RifF protein (Fig. 3).

\section{Isolation and physico-chemical properties of rifamycin biosynthesis intermediates produced by mutant 3/1}

To analyse the effect of the truncated RifF protein on rifamycin biosynthesis of mutant $3 / 1$, the strain was cultivated in the vegetative medium NL148 for $3 \mathrm{~d}$ and transferred into 11 FBR 42 medium in shake flasks. After $10 \mathrm{~d}$ cultivation, an aliquot of the culture broth was extracted with butanol. HPLC analysis of the extract showed that mutant $3 / 1$ does not produce rifamycin $B$, which is the main rifamycin produced by the parental strain N/813. On the other hand, several new compounds were detected by HPLC that were not found in strain N/813 and showed UV absorption spectra typical for compounds with a naphthoquinone chromophore.

The culture broth of the mutant $3 / 1$ was extracted with 


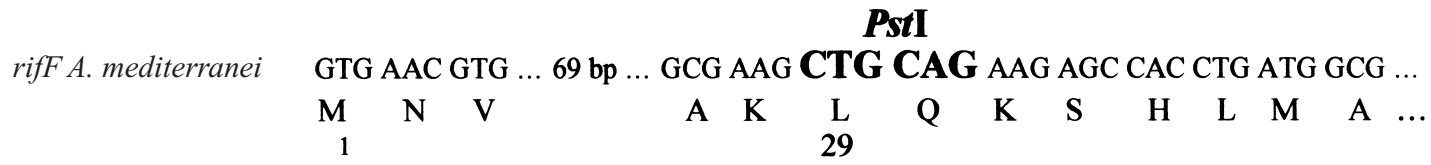

\section{9 bp deletion}

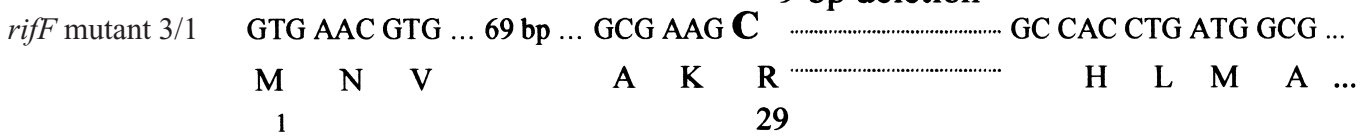

Fig. 3. Comparison of the $\mathrm{N}$-terminal parts of the Riff proteins produced by $A$. mediterranei $\mathrm{N} / 813$ and the mutant strain $3 / 1$. The $9 \mathrm{bp}$ deletion inside the riff gene and the change from L to $R$ at position 29 inside the mutated RifF protein are indicated.<smiles>C/C(C(=O)O)=C(/O)C=C(O)C(C)C(O)c1cc(N)cc(O)c1</smiles>

Module 3 intermediate P8/1-OG (1)<smiles>CC(=CC(C)C(=O)O)C(=O)c1c(O)c(C)cc2c1C(=O)C=C(N)C2=O</smiles>

Module 4 intermediate (2)<smiles>Cc1cc2c(c(C(=O)/C=C/C(C)[C@@H](O)[C@H](C)C(=O)O)c1O)C(=O)C=C(N)C2=O</smiles>

Module 5 intermediate (3)<smiles>CC(=CC(C)[C@H]1OC(=O)[C@H](C)[C@@H](O)[C@@H]1C)C(=O)c1c(O)c(C)cc2c1C(=O)C=C(N)C2=O</smiles>

Module 6 intermediate (4)<smiles>C/C(=C\C(C)[C@@H](O)[C@@H](C)[C@H](O)[C@H](C)[C@H](O)[C@H](C)C(=O)O)C(=O)c1c(O)c(C)cc2c1C(=O)C=C(N)C2=O</smiles>

Module 7 intermediate (5)<smiles>C/C(=C\C(C)[C@@H](O)[C@@H](C)[C@H](O)[C@H](C)[C@H]1OC(=O)[C@H](C)[C@H](O)[C@H]1C)C(=O)c1c(O)c(C)cc2c1C(=O)C=C(N)C2=O</smiles>

Module 8 intermediate (6)<smiles>C/C(=C/C(C)[C@@H](O)[C@@H](C)[C@@H](O)[C@@H](C)[C@H](O)[C@H](C)[C@H](O)[C@H](C)/C=C/C(=O)O)C(=O)c1c(O)c(C)cc2c1C(=O)C=C(N)C2=O</smiles>

Module 9 intermediate (7)

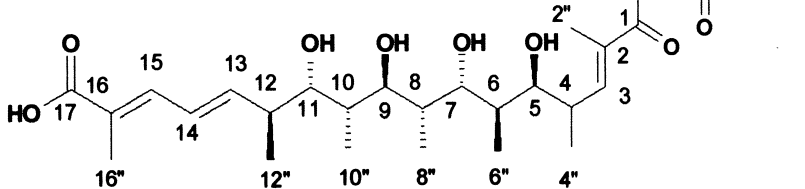

Module 10 intermediate (8)

Fig. 4. Structures of rifamycin biosynthesis intermediates 1 to 8 released from modules 3 to 10 . 
Table 1. Physico-chemical and chromatographical properties of rifamycin biosynthesis intermediates 1 to 8 released from modules 3 to 10

ESI-MS, electrospray ionized mass spectroscopy.

\begin{tabular}{|c|c|c|c|c|c|}
\hline $\begin{array}{l}\text { (Intermediate) } \\
\text { from module }\end{array}$ & Formula & $\begin{array}{c}\text { ESI-MS } \\
\qquad(\boldsymbol{m} / \boldsymbol{z})\end{array}$ & $\begin{array}{l}\mathrm{UV} \lambda \text { max. } \\
(\mathrm{MeOH} ; \mathbf{n m})\end{array}$ & $\begin{array}{r}\text { TLC } \\
\boldsymbol{R}_{F}^{*}\end{array}$ & $\begin{array}{r}\text { HPLC } \\
(\min )\end{array}$ \\
\hline (1) 3 & $\begin{array}{c}\mathrm{C}_{15} \mathrm{H}_{19} \mathrm{NO}_{6} \\
(309)\end{array}$ & $\begin{array}{c}291 \\
\left(\mathrm{M}-\mathrm{H}_{2} \mathrm{O}\right)\end{array}$ & 295,205 & $0 \cdot 33$ & $0 \cdot 65$ \\
\hline (2) 4 & $\begin{array}{c}\mathrm{C}_{18} \mathrm{H}_{17} \mathrm{NO}_{6} \\
(343)\end{array}$ & $\begin{array}{c}299 \\
(\mathrm{M}-\mathrm{COOH})\end{array}$ & $464,323,274,219$ & $0 \cdot 40$ & $5 \cdot 02$ \\
\hline (3) 5 & $\begin{array}{c}\mathrm{C}_{21} \mathrm{H}_{23} \mathrm{NO}_{7} \\
(401)\end{array}$ & 401 & $461,323,274,222$ & $0 \cdot 38$ & $4 \cdot 91$ \\
\hline $\begin{array}{l}\text { (4) } 6 \\
\text { (lactone) }\end{array}$ & $\begin{array}{c}\mathrm{C}_{24} \mathrm{H}_{27} \mathrm{NO}_{7} \\
(441)\end{array}$ & 441 & $461,323,274,222$ & $0 \cdot 67$ & $5 \cdot 31$ \\
\hline (5) 7 & $\begin{array}{c}\mathrm{C}_{27} \mathrm{H}_{35} \mathrm{NO}_{9} \\
(517)\end{array}$ & 517 & $461,323,271,226$ & $0 \cdot 36$ & $5 \cdot 25$ \\
\hline $\begin{array}{l}\text { (6) } 8 \\
\text { (lactone) }\end{array}$ & $\begin{array}{c}\mathrm{C}_{30} \mathrm{H}_{39} \mathrm{NO}_{9} \\
(557)\end{array}$ & 557 & $461,323,271,222$ & $0 \cdot 65$ & $5 \cdot 50$ \\
\hline (7) 9 & $\begin{array}{c}\mathrm{C}_{32} \mathrm{H}_{43} \mathrm{NO}_{10} \\
(601)\end{array}$ & 601 & $461,321,271,215$ & $0 \cdot 35$ & $5 \cdot 64$ \\
\hline (8) 10 & $\begin{array}{c}\mathrm{C}_{35} \mathrm{H}_{47} \mathrm{NO}_{10} \\
(641)\end{array}$ & 641 & $461,321,266,224$ & $0 \cdot 53$ & $6 \cdot 35$ \\
\hline
\end{tabular}

*Silica gel plates Merck $60 \mathrm{~F}_{254}, \mathrm{CH}_{2} \mathrm{Cl}_{2} / \mathrm{MeOH} / \mathrm{H}_{2} \mathrm{O} 70: 25: 4$ by vol.

† Column HP/HPV Shield RP8 $3.5 \mu \mathrm{m}, 3.9 \times 50 \mathrm{~mm}$ (Waters); gradient $\mathrm{H}_{2} \mathrm{O}$ (A)-acetonitrile (B) $(10-100 \% \mathrm{~B}$ in $9 \mathrm{~min})$.

ethyl acetate and by chromatographical separations the new rifamycin-biosynthesis intermediates 2 to 8 released from modules 4 to 10 (Fig. 4) as well as the starter unit AHBA and the known early intermediate P8/1-OG (Ghisalba et al., 1981) (1) were obtained in pure form. P8/1-OG (intermediate $\mathbf{1}$ ) is produced as the main intermediate and was identified by comparison of its spectroscopic properties with published data. The presence of the free acid form 1 was determined by IR spectroscopy (band at $2650 \mathrm{~cm}^{-1}$ ). The physico-chemical and chromatographic parameters of the new intermediates are shown in Table 1.

\section{Elucidation of the structure of rifamycin-biosynthesis intermediates 2 to 8}

Elucidation of the structure of the new rifamycin biosynthesis intermediates 2 to 8 released from modules 4 to 10 , respectively, are based on spectroscopic data (UV, IR, NMR and MS; Table 2); intermediate 7 released from module 9 is used to exemplify the procedure here.

Intermediate $\mathbf{7}$ from module 9 . The UV absorptions at 315 , 276 and $203 \mathrm{~nm}$, which are common to the whole series of intermediates 2 to 8 released from modules 4 to 10 and in distinct contrast to the UV spectrum of the known intermediate P8/1-OG (1) released by module 3, clearly indicates a naphthoquinone ring system, as present in rifamycin B. From high resolution ESI-MS (electrospray ionized mass spectroscopy) $(\mathrm{m} / z$ 624.27895) the molecular formula $\mathrm{C}_{32} \mathrm{H}_{43} \mathrm{NO}_{10}$ resulted for intermediate 7 . The IR spectrum shows prominent bands at 1624 $(\mathrm{C}=\mathrm{O})$ and $971 \mathrm{~cm}^{-1}(\mathrm{C}=\mathrm{C}$ trans $)$. The substitution pattern of the naphthoquinone ring is supported by the two singlets in the ${ }^{1} \mathrm{H}$ NMR spectrum (Fig. 5) at $7 \cdot 57$ p.p.m. $\left(8^{\prime}-\mathrm{H}\right)$ and $5 \cdot 38$ p.p.m. $\left(3^{\prime}-\mathrm{H}\right)$, the methyl signal at 1.98 p.p.m. $\left(11^{\prime}-\mathrm{H}_{3}\right)$ and the broad signal of the amino group $\left(2^{\prime}-\mathrm{NH}_{2}\right)$ at 6.8 p.p.m. The aliphatic chain, substituted with five secondary methyl groups (five doublets in the range of 0.75 to 0.96 p.p.m.), one methyl group bound to a double bond conjugated to carbonyl1 (singlet at 1.85 p.p.m.) and four methine carrying a hydroxy group was deduced from two-dimensional DQF-COSY (double quantum filtered correlated spectroscopy) NMR measurements (Fig. 6). The trans double bond at the carboxy end is revealed by the multiplet $(\mathrm{d} \times \mathrm{d})$ at 6.95 p.p.m. $(13-\mathrm{H})$ and the doublet at $5 \cdot 75$ p.p.m. (14-H, $J=16 \mathrm{~Hz})$.

Intermediate 4 released from module 6 . The UV and IR spectra resemble very closely the corresponding spectra of compound 7, except the much stronger band at $1720-1730 \mathrm{~cm}^{-1}$ observed in the IR spectrum of 7 . In the proton NMR spectrum, the signal for the methine- 5 is shifted downfield to 4.05 p.p.m. (compared to 3.50 p.p.m. in 7). These spectroscopic data, together with the molecular formula $\mathrm{C}_{24} \mathrm{H}_{27} \mathrm{NO}_{7}$ from MS $(\mathrm{m} / z$ $442 \mathrm{MH}^{+}$), gave evidence for the presence of a 6membered lactone ring between the terminal carboxy 
Table 2. ${ }^{1} \mathrm{H}$ NMR data for rifamycin biosynthesis intermediates 2 to 8 released from modules 4 to 10 (in $d_{6}$-DMSO)

The occurrence of atropic isomers at $25^{\circ} \mathrm{C}$ may be due to either tautomeric forms and/or hindered rotation around the $5^{\prime} 1$-carbon bond. The ratio of the two forms differ from 1:1 for intermediates 2 to 6 to $9: 1$ for intermediates 7 and 8 . When the temperature is increased, the signals of the two forms collapse.

\begin{tabular}{|c|c|c|c|c|c|c|c|}
\hline \multirow[t]{2}{*}{ Position } & \multicolumn{7}{|c|}{ Intermediate } \\
\hline & 2 & 3 & $\begin{array}{c}4^{*} \\
\text { (lactone) }\end{array}$ & $5 \dagger$ & $6^{*}$ & $\begin{array}{c}7 \\
\text { (lactone) }\end{array}$ & $8 *$ \\
\hline $2^{\prime}-\mathrm{NH}_{2}$ & $7 \cdot 1(\mathrm{br})$ & $6 \cdot 8(\mathrm{br})$ & $6 \cdot 61(\mathrm{br})$ & 6.52 (br) & $6 \cdot 46(\mathrm{br})$ & $6 \cdot 8$ (br) & $6 \cdot 8(\mathrm{br})$ \\
\hline $3^{\prime}-\mathrm{H}$ & $5 \cdot 58(\mathrm{~s})$ & $5 \cdot 39(\mathrm{~m})$ & $5 \cdot 67(\mathrm{~s})$ & $5 \cdot 69(\mathrm{~s})$ & $5 \cdot 54(\mathrm{~s})$ & $\begin{array}{l}5 \cdot 38(\mathrm{~s}) \\
5 \cdot 45(\mathrm{~s})\end{array}$ & $5 \cdot 39(\mathrm{~s})$ \\
\hline $8^{\prime}-\mathrm{H}$ & $7 \cdot 80(\mathrm{~s})$ & $7 \cdot 55(\mathrm{~m})$ & $7 \cdot 77(\mathrm{~s})$ & $7 \cdot 79(\mathrm{~s})$ & $7 \cdot 67(s)$ & $7 \cdot 57(s)$ & $7 \cdot 58(\mathrm{~s})$ \\
\hline $11^{\prime}-\mathrm{H}_{3}$ & $\begin{array}{l}2 \cdot 30(\mathrm{~s}) \\
2 \cdot 28(\mathrm{~s})\end{array}$ & $\begin{array}{l}2 \cdot 00(\mathrm{~s}) \\
1.97(\mathrm{~s})\end{array}$ & $2 \cdot 31(\mathrm{~s})$ & $2 \cdot 28(\mathrm{~s})$ & $2 \cdot 15(\mathrm{~s})$ & $1.98(\mathrm{~s})$ & $1.99(\mathrm{~s})$ \\
\hline $6^{\prime}-\mathrm{OH}$ & & & & $9 \cdot 3(\mathrm{br})$ & & & \\
\hline $2^{\prime \prime}-\mathrm{H}_{3}$ & $1.90(\mathrm{~s})$ & $\begin{array}{l}1.80(\mathrm{~s}) \\
1.72(\mathrm{~s})\end{array}$ & $1 \cdot 91(\mathrm{~s})$ & $1.92(\mathrm{~s})$ & $1.88(\mathrm{~s})$ & $1 \cdot 85(\mathrm{~s})$ & $1 \cdot 82(\mathrm{~s})$ \\
\hline $3-\mathrm{H}$ & $\begin{array}{l}5.95(\mathrm{~d}) \\
5.90(\mathrm{~d})\end{array}$ & $6 \cdot 13(d)$ & $5.98(\mathrm{~d})$ & $6.09(\mathrm{~d})$ & $6 \cdot 12(d)$ & $6 \cdot 32(d)$ & $6 \cdot 28(\mathrm{~d})$ \\
\hline 4-H & $3 \cdot 40(\mathrm{~m})$ & $2 \cdot 52(\mathrm{~m})$ & $2 \cdot 80(\mathrm{~m})$ & $2 \cdot 65(\mathrm{~m})$ & $2 \cdot 65(\mathrm{~m})$ & $2.69(\mathrm{~m})$ & $2 \cdot 63(\mathrm{~m})$ \\
\hline $4^{\prime \prime}-\mathrm{H}_{3}$ & $\begin{array}{l}1 \cdot 10(\mathrm{~d}) \\
1 \cdot 03(\mathrm{~d})\end{array}$ & $0 \cdot 88(\mathrm{~d})$ & $0 \cdot 91(\mathrm{~d})$ & $0 \cdot 86(\mathrm{~d})$ & $0 \cdot 86(\mathrm{~d})$ & $0 \cdot 87(\mathrm{~d})$ & $0 \cdot 84(\mathrm{~d})$ \\
\hline $5-\mathrm{H}$ & - & $3 \cdot 35(\mathrm{~d})$ & $4 \cdot 05(\mathrm{~d})$ & $3 \cdot 65(\mathrm{~m})$ & $3 \cdot 60(\mathrm{dd})$ & $3 \cdot 40(\mathrm{~d})$ & 3.42 (br s) \\
\hline $6-\mathrm{H}$ & & $2 \cdot 08(\mathrm{dd})$ & $2 \cdot 11(\mathrm{~m})$ & $1.74(\mathrm{~m})$ & $1 \cdot 61(\mathrm{~m})$ & $1 \cdot 85(\mathrm{~m})$ & $1 \cdot 84(\mathrm{~m})$ \\
\hline $6^{\prime \prime}-\mathrm{H}_{3}$ & & $1 \cdot 00(\mathrm{~d})$ & $0.82(\mathrm{~d})$ & $0 \cdot 86(\mathrm{~d})$ & $0 \cdot 71(\mathrm{~d})$ & $0.75(\mathrm{~d})$ & $0 \cdot 70(\mathrm{~d})$ \\
\hline $7-\mathrm{H}$ & & - & $3 \cdot 63(\mathrm{~m})$ & $3.58(\mathrm{~m})$ & $3.78(\mathrm{~m})$ & $4 \cdot 20(\mathrm{~d})$ & $4 \cdot 15(\mathrm{~d})$ \\
\hline $8-\mathrm{H}$ & & & $2 \cdot 22(\mathrm{dd})$ & $1.57(\mathrm{~m})$ & $1 \cdot 84(\mathrm{~m})$ & $1.52(\mathrm{~m})$ & $1.52(\mathrm{~m})$ \\
\hline $8^{\prime \prime}-\mathrm{H}_{3}$ & & & $1 \cdot 21(\mathrm{~d})$ & $0 \cdot 66(d)$ & $0 \cdot 93(\mathrm{~d})$ & $0 \cdot 68(\mathrm{~d})$ & $0 \cdot 67(\mathrm{~d})$ \\
\hline $9-\mathrm{H}$ & & & - & $3.78(\mathrm{~d})$ & $3 \cdot 94(\mathrm{~m})$ & $3 \cdot 50(\mathrm{~d})$ & $3 \cdot 47(\mathrm{dd})$ \\
\hline $10-\mathrm{H}$ & & & & $2 \cdot 63(\mathrm{~m})$ & $2 \cdot 06(\mathrm{~m})$ & $1.79(\mathrm{~m})$ & $1 \cdot 80(\mathrm{~m})$ \\
\hline $10^{\prime \prime}-\mathrm{H}_{3}$ & & & & $1.09(\mathrm{~d})$ & $1 \cdot 00(\mathrm{~d})$ & $0.96(\mathrm{~d})$ & $0.93(\mathrm{~d})$ \\
\hline $11-\mathrm{H}$ & & & & - & $3.56(d)$ & $3.64(\mathrm{~d})$ & $3.56(d)$ \\
\hline $12-\mathrm{H}$ & & & & & $2 \cdot 68(\mathrm{~d})$ & $2 \cdot 36(\mathrm{dd})$ & $2 \cdot 28(\mathrm{~m})$ \\
\hline $12^{\prime \prime}-\mathrm{H}_{3}$ & & & & & $1 \cdot 12(\mathrm{~d})$ & $0.89(\mathrm{~d})$ & $0 \cdot 88(\mathrm{~d})$ \\
\hline $13-\mathrm{H}$ & & & & & - & $6.95(\mathrm{dd})$ & $6 \cdot 00(\mathrm{dd})$ \\
\hline $14-\mathrm{H}$ & & & & & & $5 \cdot 75(\mathrm{~d})$ & $7 \cdot 01(\mathrm{dd})$ \\
\hline $15-\mathrm{H}$ & & & & & & - & $6 \cdot 46(\mathrm{~d})$ \\
\hline $16^{\prime \prime}-\mathrm{H}_{3}$ & & & & & & & $1 \cdot 85(\mathrm{~s})$ \\
\hline
\end{tabular}

*Shifts at $100{ }^{\circ} \mathrm{C}$.

† Shifts at $120^{\circ} \mathrm{C}$.

$\ddagger$ Shifts at $80^{\circ} \mathrm{C}$.

group and the hydroxy group at C-5. The analogous situation is found in intermediate $\mathbf{6}$ released from module 8 , which contains a lactone ring built by the hydroxy function at C-9.

Intermediate 8 released from module 10. In NMR ROESY (rotated frame nuclear Overhauser enhancement spectroscopy) experiments, a strong nuclear Overhauser enhancement (NOE) is measured between the protons of the methyl group at C-16 and the olefinic proton at C14 , thus indicating the geometry of the terminal carbon double bond as trans.

\section{Determination of the relative stereochemistry}

As intermediates 4 and 6 released from modules 6 and 8 contain a 6-membered lactone ring, the relative stereochemistry for the two carbon sequences C-5, C-6, C-7, C-8 and C-9, C-10, C-11, C-12, respectively, could be deduced from measurements of coupling constants in proton NMR spectra and from NOE experiments (Fig. 7). The overlapping carbon sequence C-7, C-8, C-9, C10 is covered by the lactone form of the intermediate released from module 7 , which was found in addition to the corresponding linear intermediate 5 . The results, 


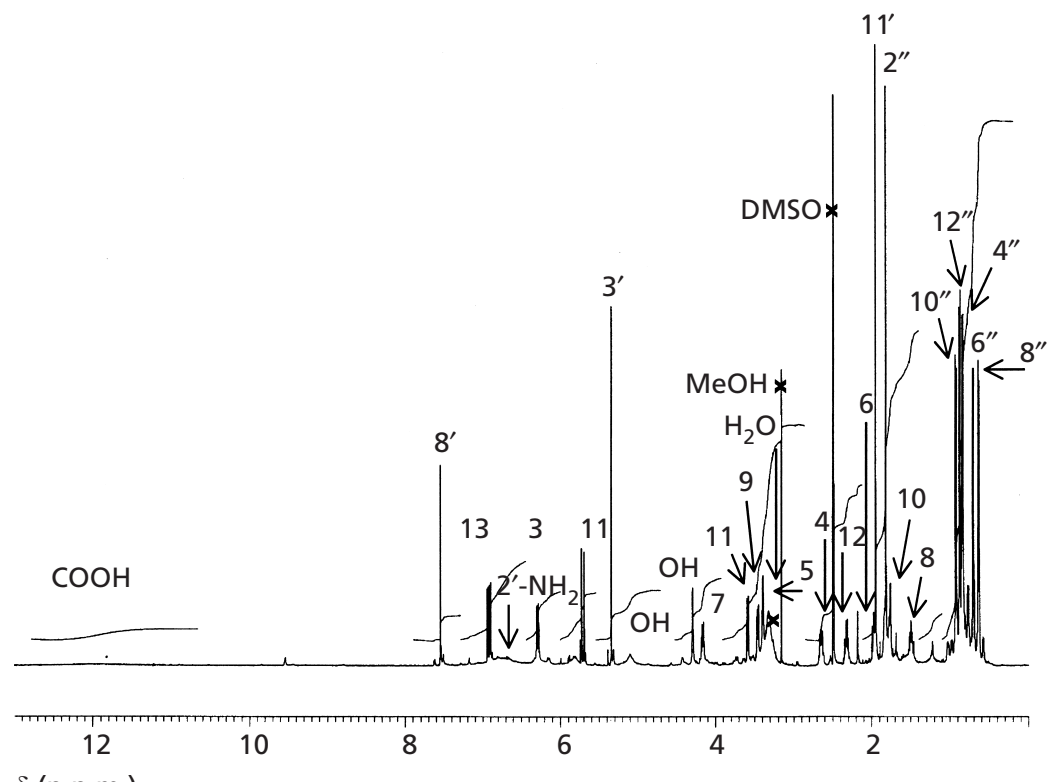

$\delta$ (p.p.m.)
Fig. 5. ${ }^{1} \mathrm{H}$ NMR spectrum of rifamycin biosynthesis intermediate 7 released from module 9 (in $d_{6}$-DMSO). therefore, revealed the complete relative configurations for the methine carbons of the side chain (except for $\mathrm{C}-4$ which is achiral in the final rifamycins); the determined relative stereochemistry corresponds to the known absolute chirality of the ansa ring in the rifamycins (Brufani et al., 1964).

\section{DISCUSSION}

In this work we have described the inactivation of the rifF gene in the rifamycin B biosynthesis gene cluster and the production of a series of linear rifamycin $\mathrm{B}$ bio- synthesis intermediates by the corresponding mutant strain 3/1. Interestingly, all intermediates 1 to 8 released from modules 3 to 10 were obtained, whereas the intermediates produced by modules 1 and 2 have not been detected so far. The absence of these compounds in the culture broth of mutant strain $3 / 1$ may result from an efficient conversion of these intermediates to P8/1OG (1), which was found as the predominant compound.

The RifF protein shows a high degree of similarity to different arylamine $\mathrm{N}$-acetyltransferases, e.g. of $\mathrm{Myco-}$

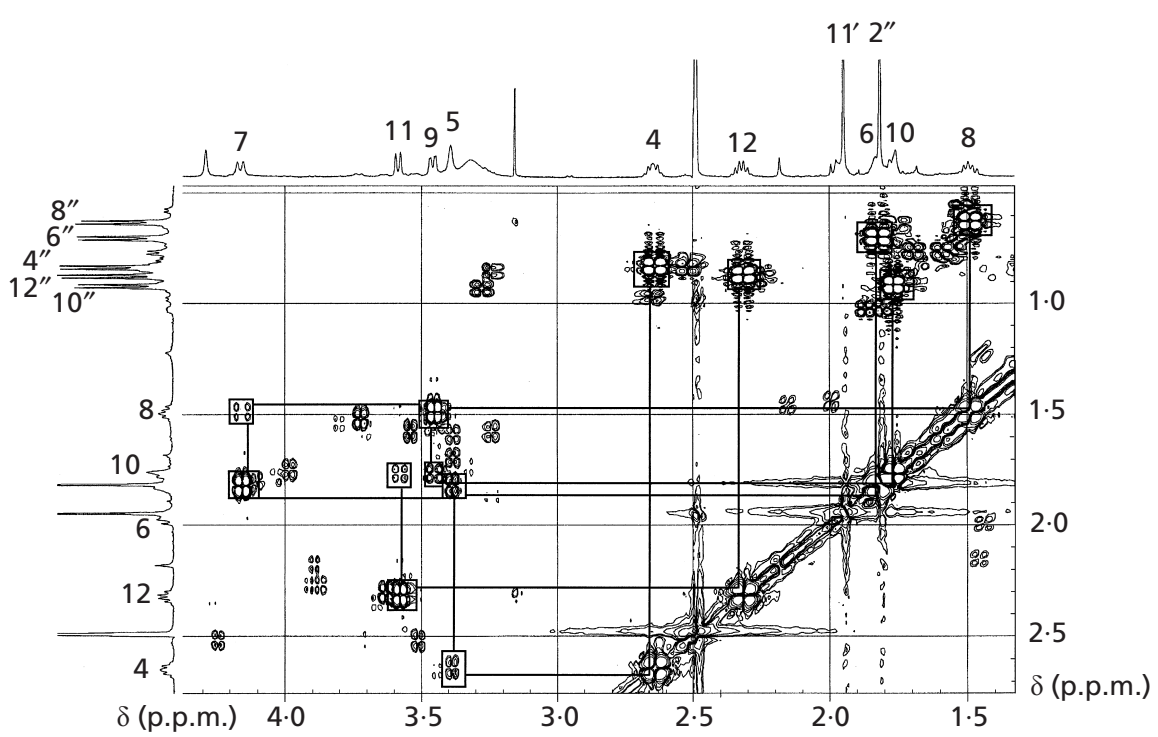

Fig. 6. DQF-COSY (double quantum filtered correlated spectroscopy) ${ }^{1} \mathrm{H}$ NMR spectrum of rifamycin biosynthesis intermediate 7 released from module 9 (in $d_{6}$-DMSO). 


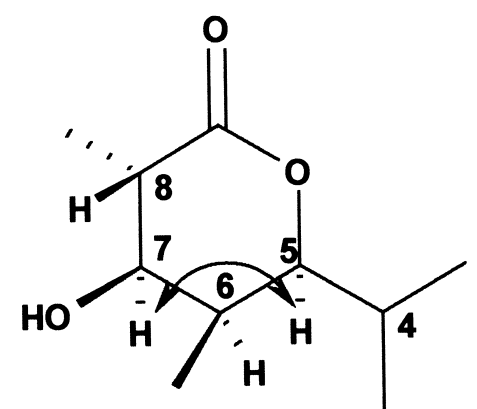

Module 6 intermediate 4 (lactone)

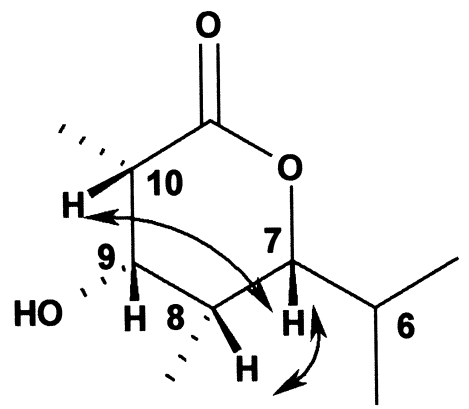

Module 7 intermediate 5 lactone

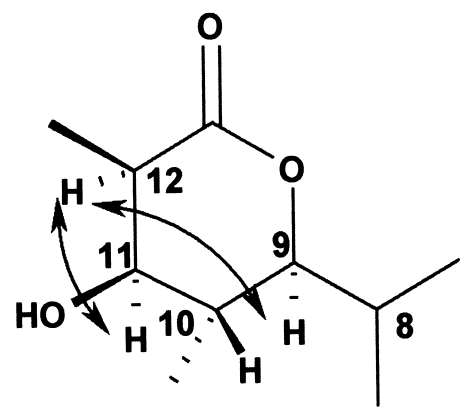
Module 8 intermediate 6
(lactone)

\section{Coupling constants:}

\begin{tabular}{l|r}
$\mathrm{H}$ atoms & $J(\mathrm{~Hz})$ \\
\hline $5-6$ & $2 \cdot 0$ \\
$6-7$ & $4 \cdot 3$ \\
$7-8$ & $10 \cdot 9$
\end{tabular}

\begin{tabular}{c|c}
$\mathrm{H}$ atoms & $J(\mathrm{~Hz})$ \\
\hline $7-8$ & $3 \cdot 0$ \\
$8-9$ & $7 \cdot 9$ \\
$9-10$ & $6 \cdot 1$
\end{tabular}

\begin{tabular}{r|c}
$\mathrm{H}$ atoms & $J(\mathrm{~Hz})$ \\
\hline $9-10$ & $8 \cdot 0$ \\
$10-11$ & $2 \cdot 8$ \\
$11-12$ & $3 \cdot 3$
\end{tabular}

Fig. 7. Relative stereochemistry in the corresponding lactones of intermediates 4,5 and 6 released from modules 6,7 and 8. The arrows on the chemical structures represent strong nuclear Overhauser enhancement (NOE).

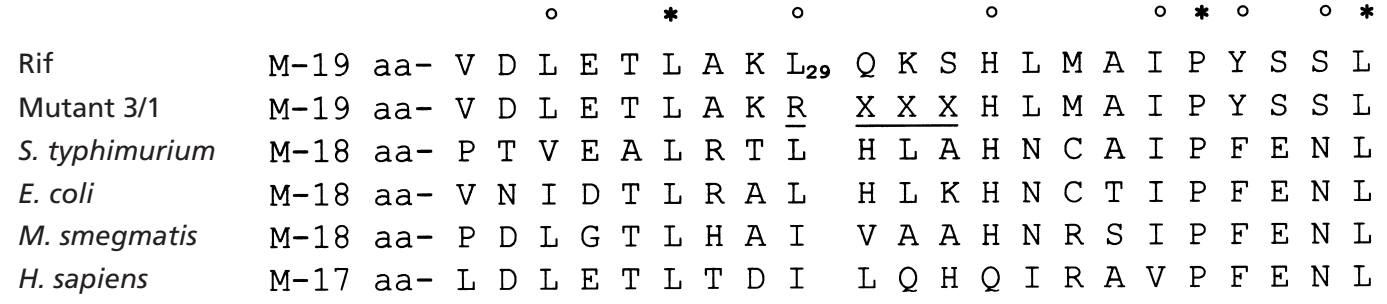

Fig. 8. Alignment of the RifF protein and the inactivated RifF protein produced by the mutant strain $3 / 1$ with arylamine $\mathrm{N}$-acetyltransferases from different organisms. GenBank accession numbers are shown in parentheses. S. typhimurium, Salmonella typhimurium (Q00267); E. coli (P77567); M. smegmatis, Mycobacterium smegmatis (O86309); H. sapiens, Homo sapiens (015159). The altered or lost amino acids in the mutated RifF protein are underlined. Only the N-terminal regions of the proteins are shown. Identical $\left({ }^{*}\right)$ or similar $\left({ }^{\circ}\right)$ amino acids are marked above the sequences.

bacterium smegmatis ( $36 \cdot 5 \%$ identity over 178 aa), of $E$. coli $(28 \%$ identity over 230 aa). These sequence similarities together with our results demonstrate the function of the rifF gene product as a cyclase (rifamycin amide synthase) performing the intramolecular ring closure by amide bond formation between the carboxyl group at one end and the amino group at the opposite end of the mature linear polyketide molecule synthesized by the rifamycin PKS. The role of the RifF protein in rifamycin B biosynthesis is therefore the cyclization and simultaneous release of the polyketide chain from the acyl carrier protein of module 10 of the rifamycin PKS.
Mutant strain 3/1 produced a series of linear intermediates of the rifamycin B biosynthesis and not, as expected, only the full-length linear intermediate produced by module 10 . To explain this result, the activity of a second enzyme is needed that is able to catalyse the release of the linear intermediates from the acyl carrier proteins of modules 3 to 10 . The thioesterase encoded by orf12 (August et al., 1998), almost $30 \mathrm{~kb}$ downstream of rifF, may be the protein having this function. In addition, the obstruction of the normal release of the full-length acyl chain from the rifamycin PKS probably leads to an accumulation of linear intermediates docked at the acyl 


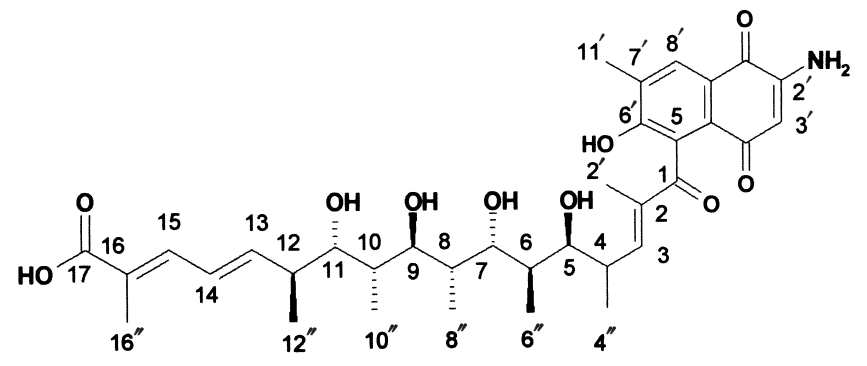

Linear intermediate produced by module 10

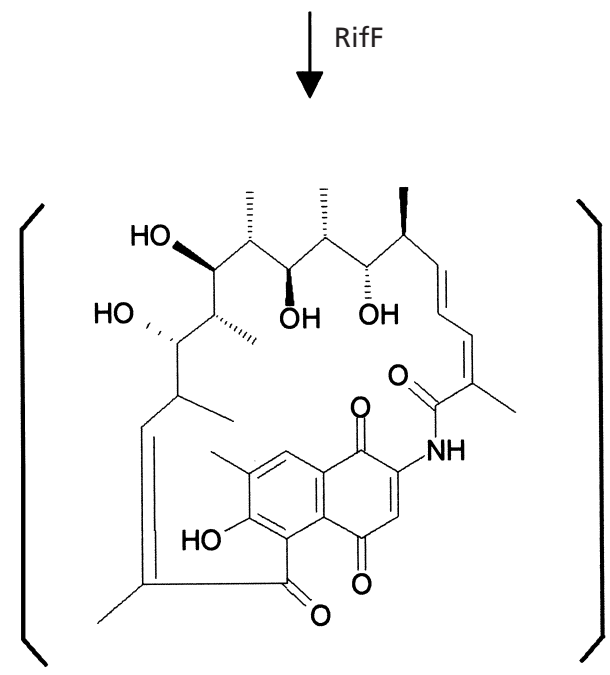

Proansamycin B

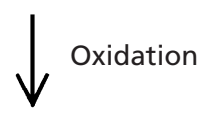

Protorifamycin I

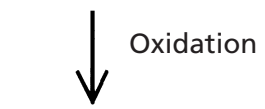

Rifamycin W

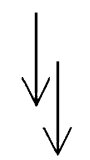

Rifamycin B

Fig. 9. Function of Riff and pathway for the biosynthesis of rifamycin B starting from the completed linear polyketide (8) released from module 10 .

carrier proteins of the different modules, which are then released from the PKS by the thioesterase, thereby preventing blockage of the enzyme complex. Such an editing activity was recently discussed for the thioesterase $\mathrm{TylO}$ in the tylosin biosynthesis (Butler et al., 1999).

Noncyclized polyketide intermediates of 16 -membered macrolides were also isolated from the culture broth of the mycinamicin producer 'Micromonospora griseorubida' sp. nov. (tetraketide and pentaketide) and the corresponding triketide in a nonproducing mutant (Kinoshita et al., 1988). Tetra- and pentaketides were observed in nonproducing mutants of the tylosin producer Streptomyces fradiae (Huber et al., 1990). These observations, together with our results, suggest that the formation of noncyclized polyketide intermediates is perhaps a general phenomenon during either the normal or impaired catalysis by type I PKS.

The introduction of the $9 \mathrm{bp}$ deletion inside the rif $F$ gene results in the loss of three amino acids $(\mathrm{Q}, \mathrm{K}$ and $\mathrm{S})$ and the exchange of $\mathrm{L}$ to $\mathrm{R}$ at position 29 (Fig. 8). These alterations in the RifF protein caused the inactivation of the enzyme because the cyclization reaction at the end of the biosynthesis of the polyketide backbone is no longer performed. The exact function of the altered or lost amino acids inside the RifF protein is not clear at the moment, but one possible candidate for an essential function for the cyclization reaction is the conserved $\mathrm{L}$ at position 29 (Fig. 8).

Furthermore we have shown that the linear intermediates released by module 4 and the following modules already have the naphthoquinone chromophore, whereas the linear intermediate released by module 3 still has the benzenoid structure derived from the AHBA starter unit. A proposal for the mechanism of the naphthoquinone unit formation was made by Tang et al. (1998); however, the timing of these reactions was not clear. The naphthoquinone structure of the intermediates derived from modules 4-10 indicates that the formation of the naphthoquinone ring takes place at the transition from module 3 to module 4 . With the results obtained it is not clear, however, if the reactions for the naphthoquinone ring formation take place with the respective intermediates bound to the rifamycin PKS or after their release from the enzyme. It seems that the transition from module 3 to module 4 is a critical step during the rifamycin B synthesis. This is strengthened by results from Hunziker et al. (1998), who showed that feeding of altered starter units, with a missing amino group at C-3 or an additional missing hydroxyl group at $\mathrm{C}-5$, to a mutant in AHBA synthesis results in a termination of the rifamycin synthesis after module 3 . In those feeding experiments, the corresponding derivatives of the well-known tetraketide shunt product P8/1OG were detected (Hunziker et al., 1998).

Different rifamycin molecules have been postulated as the earliest macrocyclic intermediates of rifamycin biosynthesis: proansamycin A or B deduced from the early intermediate protorifamycin I and structure comparison with streptovaricin precursors (Ghisalba et al., 1978, 1979) and proansamycin X, based on hypothetical intermediates of the rifamycin PKS gene cluster (August et al., 1998; Tang et al., 1998). The structure of the observed module 10 intermediate 8 and the deduced function of RifF, performing the ring closure of the linear endproduct 8 of the PKS, now provides strong evidence that proansamycin $\mathrm{B}$ is the direct macrocyclic 
product of the rifamycin PKS (Fig. 9). The presence of the trans-cis sequence for the conjugated olefinic system in rifamycin B (and its precursor proansamycin B) can be explained by migration of the $(13,14)$ trans- $(15,16)$ trans double bonds via enolysation and subsequent isomerization of the geometry. From the hypothetical proansamycin B, a simple one-step transformation, oxidation at C-4", would lead to protorifamycin I, the earliest macrocyclic precursor of the rifamycins isolated so far (Ghisalba et al., 1978).

The inactivation of the rifF gene in A. mediterranei $\mathrm{S} 699$ has also been carried out independently by $\mathrm{Yu}$ et al. (1999), whose report appeared while our paper was being reviewed.

\section{ACKNOWLEDGEMENTS}

The authors thank A. Pospiech (Novartis Services, Bioanalytik) for DNA sequencing and Ch. Quiquerez for the measurements of the MS spectra.

\section{REFERENCES}

August, P. R., Tang, L., Yoon, Y. J. \& 9 other authors (1998). Biosynthesis of the ansamycin antibiotic rifamycin: deductions from the molecular analysis of the rif biosynthetic gene cluster of Amycolatopsis mediterranei S699. Chem Biol 5, 69-79.

Bachs, L., Pares, A., Elena, M., Piera, C. \& Rodes, J. (1992). Effects of long-term rifampicin administration in primary biliary cirrhosis. Gastroenterology 102, 2077-2080.

Barakett, V., Lesage, D., Delisle, F., Vergez, P. \& Petit, J. C. (1993). Killing kinetics of vancomycin and rifamycin tested alone and in combination against penicillin-resistant Streptococcus pneumoniae. Eur J Clin Microbiol Infect Dis 12, 69-71.

Blondelet-Rouault, M.-H., Weiser, J., Lebrihi, A., Branny, P. \& Pernodet, J.-L. (1997). Antibiotic resistance gene cassettes derived from the $\Omega$ interposon for use in E. coli and Streptomyces. Gene 190, 315-317.

Brufani, M., Fedeli, W., Giacomello, G. \& Vaciago, A. (1964). The $\mathrm{X}$-ray analysis of the structure of rifamycin B. Experientia 20, 339-342.

Butler, A. R., Bate, N. \& Cundliffe, E. (1999). Impact of thioesterase activity on tylosin biosynthesis in Streptomyces fradiae. Chem Biol 6, 287-292.

Chen, S., von Bamberg, D., Hale, V., Breuer, M., Hardt, B., Müller, R., Floss, H. G., Reynolds, K. A. \& Leistner, E. (1999). Biosynthesis of ansatrienin (mycotrienin) and naphthomycin: identification and analysis of two separate biosythetic gene clusters in Streptomyces collinus Tü 1892. Eur J Biochem 261, 98-107.

Ghisalba, O., Traxler, P. \& Nüesch, J. (1978). Early intermediates in the biosynthesis of ansamycins. I. Isolation and identification of protorifamycin I. J Antibiot 31, 1124-1131.

Ghisalba, O., Traxler, P., Fuhrer, H. \& Richter, W. J. (1979). Early intermediates in the biosynthesis of ansamycins. II. Isolation and identification of proansamycins B-M1 and protorifamycin I-M1. J Antibiot 32, 1267-1272.

Ghisalba, O., Fuhrer, H., Richter, W. J. \& Moss, S. (1981). A genetic approach to the biosynthesis of the rifamycin chromophore in Nocardia mediterranei. III. Isolation and identification of an early aromatic ansamycin precursor containing the seven-carbon amino starter-unit and three initial acetate/propionate units of the ansa chain. J Antibiot 34, 58-63.

Ghisalba, O., Auden, J. A. L., Schupp, T. \& Nüesch, J. (1984). The rifamycins: properties, biosynthesis, and fermentation. In Biotechnology of Industrial Antibiotics, pp. 281-327. Edited by E. J. Vandamme. New York \& Basel: Marcel Dekker.

Hanahan, D. (1983). Studies on transformation of Escherichia coli with plasmids. J Mol Biol 166, 557-580.

Huber, M. L. B., Paschal, J. W., Leeds, J. P., Kirst, H. A., Wind, J. A., Miller, F. D. \& Turner, J. R. (1990). Branched-chain fatty acids produced by mutants of Streptomyces fradiae, putative precursors of the lactone ring of tylosin. Antimicrob Agents Chemother 34, 1535-1541.

Hunziker, D., Yu, T.-W., Hutchinson, C. R., Floss, H. G. \& Khosla, C. (1998). Primer unit specificity in rifamycin biosynthesis principally resides in the later stages of the biosynthetic pathway. $J$ Am Chem Soc 120, 1092-1093.

Kinoshita, K., Takenaka, S. \& Hayashi, M. (1988). Isolation of proposed intermediates in the biosynthesis of mycinamicins. $J$ Chem Soc Chem Commun 1988, 943-945.

MacNeil, D. J., Gewain, K. M., Ruby, C. L., Dezeny, G., Gibbons, P. H. \& MacNeil, T. (1992). Analysis of Streptomyces avermitilis genes required for avermectin biosynthesis utilizing a novel integration vector. Gene 111, 61-68.

Miller, J. H. (1972). Experiments in Molecular Genetics. Cold Spring Harbor, NY: Cold Spring Harbor Laboratory.

Oppenheim, B., Koornhof, H. J. \& Austrian, R. (1986). Antibioticresistant pneumococcal disease in children at Baragwanath hospital, Johannesburg. Pediatr Infect Dis 5, 520-524.

Pospiech, A. \& Neumann, B. (1995). A versatile quick-prep of genomic DNA from Gram-positive bacteria. Trends Genet 11, 217-218.

Sambrook, J., Fritsch, E. F. \& Manniatis, T. (1989). Molecular Cloning: a Laboratory Manual, 2nd edn. Cold Spring Harbor, NY : Cold Spring Harbor Laboratory.

Schupp, T. \& Divers, M. (1986). Protoplast preparation and regeneration in Nocardia mediterranei. FEMS Microbiol Lett 36, 159-162.

Schupp, T., Toupet, C., Engel, N. \& Goff, S. (1998). Cloning and sequence analysis of the putative rifamycin polyketide synthase gene cluster from Amycolatopsis mediterranei. FEMS Microbiol Lett 159, 201-207.

Szabo, C., Bissel, M. J. \& Calvin, M. (1976). Inhibition of infectious rous sarcoma virus production by a rifamycin derivative. $J$ Virol 18, 445-453.

Tang, L., Yoon, Y. J., Choi, C.-Y. \& Hutchinson, C. R. (1998). Characterization of the enzymatic domains in the modular polyketide synthase involved in rifamycin B biosynthesis by Amycolatopsis mediterranei. Gene 216, 255-265.

Wehrli, W. (1977). Ansamycins: chemistry, biosynthesis and biological activity. Topics Curr Chem 72, 21-49.

Yu, T.-W., Shen, Y., Doi-Katayama, Y., Tang, L., Park, C., Moore, B. S., Hutchinson, C. R. \& Floss, H. G. (1999). Direct evidence that the rifamycin polyketide synthase assembles polyketide chains processively. Proc Natl Acad Sci USA 96, 9051-9056.

Zimmerli, W., Widmer, A. F., Blatter, M., Frei, R. \& Ochsner, P. E. (1998). Role of rifampin for treatment of orthopedic implantrelated staphylococcal infections: a randomized controlled trial. J Am Med Assoc 279, 1537-1541.

Received 9 August 1999; accepted 3 September 1999. 